\title{
Two-cycle curriculum - bachelor-master structure according to the Bologna agreement: the Swiss experience in Basle
}

\author{
H.J. Kaiser, C. Kiessling
}

\section{Summary}

In the autumn of 2006, the first cohort of students started with the bachelor programme in Basle. The whole curriculum had to be changed from the old system to the new twocycle system. The implementation of the Bologna reform in Switzerland has been successful especially with regard to the very tight time schedule. Ongoing evaluation will detect fields for improvement which will of course arise in such a fundamental process of change. A major challenge for the future will be the sustainable consolidation of high quality in medical education. (Kaiser HJ, Kiessling C. Two-cycle curriculum - bachelormaster structure according to the Bologna agreement: the Swiss experience in Basle. Netherlands Jounal of Medical Education 2010;29(1):22-19)

\section{The pre-Bologna period in}

\section{Switzerland}

Medical education in Switzerland has been undergoing continuous reform since the mid-1990s. The first reform process was triggered by increasing awareness that changes in the requirements of physicians would necessitate concomitant, essential changes in medical education. The World Health Organization's (WHO) definition of health ("Health is a state of complete physical, mental and social wellbeing and not merely the absence of disease or infirmity.") ${ }^{1}$ and the definition of the new medical doctor (WHO 5* doctor: care provider, decision maker, communicator, community leader and manager $)^{2}$ were major drivers for curriculum change, which accentuated the following aspects:

- Effective self-directed life-long learning

- Critical reasoning

- The application of scientific methods

- Communication, ethical, social and economic competencies.
Under the mandate of the Joint Commission of the Swiss Medical Schools (SMIFK/CIMS), which is a joint body of the Swiss Faculties of Medicine and the federal authorities involved in medical teaching and training, in 2002 the Swiss Catalogue of Learning Objectives for Undergraduate Medical Training (SCLO) was established. ${ }^{3}$ In 2003/2004, it was decided to revise the SCLO, which led to the present version, which was approved by the SMIFK/CIMS in 2008. The requirements resulting from the Bologna accord were taken into account in preparing the 2008 revision. All Swiss medical schools have to comply with the SCLO, which will be the basis for the new federal examination which will be developed in the summer of 2011.

\section{The pre-Bologna period in Basle}

Since 1996, the Medical Faculty of Basle has made considerable changes to its medical education programme. The first reform resulted in integration of discipline-related content and a division of the 
six-year curriculum into three parts: the first and second year, focused on the healthy body; the third and fourth year dealing with the sick body; and years five and six, dedicated to clinical experience, clinical reasoning, differential diagnosis, and synthesis. In a later reform, organ system-related units, linking preclinical and clinical disciplines, as well as problem-based learning were implemented from the first year onwards. The Basle faculty also decided that the curriculum would be a hybrid one with both teacherand student-centred formats. A pilot accreditation process generated more ideas for change and led to a more prominent role of subjects concerning social and preventive medicine, psychosomatic aspects, doctor-patient-communication and ethics. ${ }^{4-5}$ As a result of these changes, new exam formats, including the objective structured clinical examination (OSCE), were introduced to assess knowledge and skills.

\section{Implementation of Bologna in Switzerland}

In 2003, after the Swiss University Conference (SUK) had declared that medical education and dental education were not excluded from the Bologna process, it was decided to reorganize the curriculum in accordance with the Bologna criteria. Policy makers also made a strong contribution to the discussion about the Bologna process in medicine. The Rectors' Conference of the Swiss Universities (CRUS) published a paper in 2004, introducing a two-cycle curriculum in line with the Bologna declaration. ${ }^{6}$ Elaboration of these ideas by the SMIFK Bologna working group resulted in a bachelor-master model for medical education in Switzerland, which was given unanimous approval by the Rectors' Conference of the Swiss Universities in April 2005. The model is based on the concept of medical education as an integral programme, with a three-year bachelor programme fol-

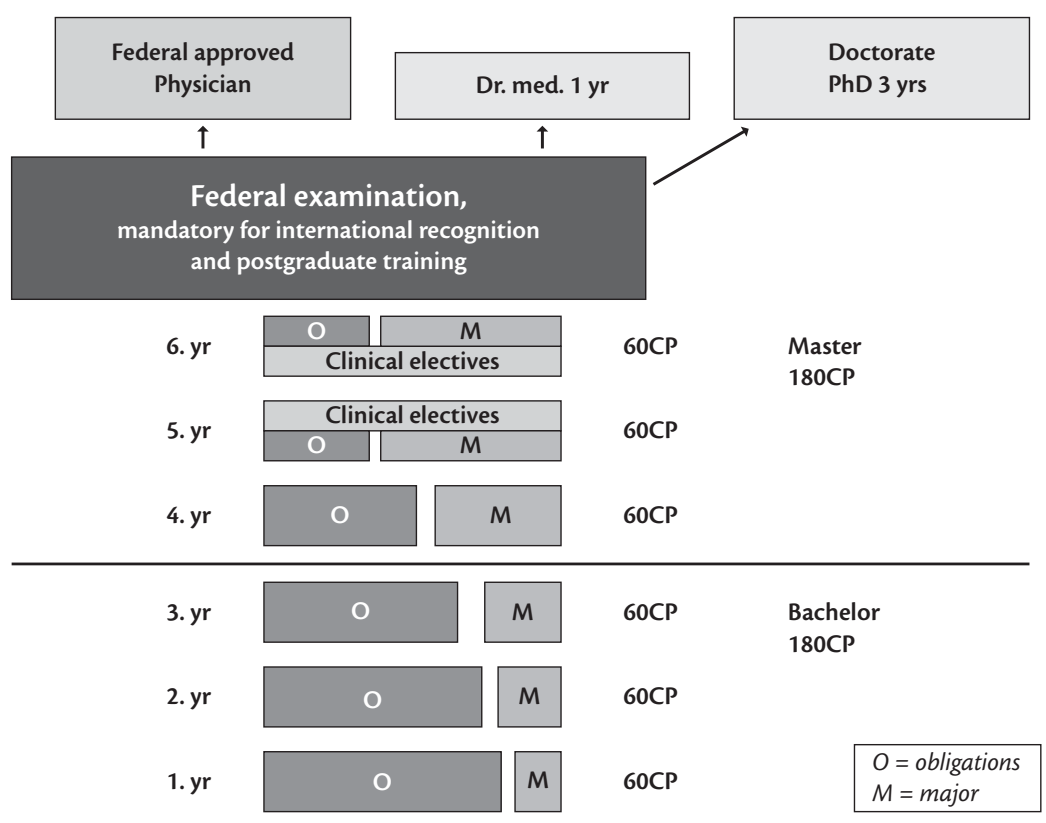

Figure 1 Bologna Model of Medical Studies: Physician Track. 


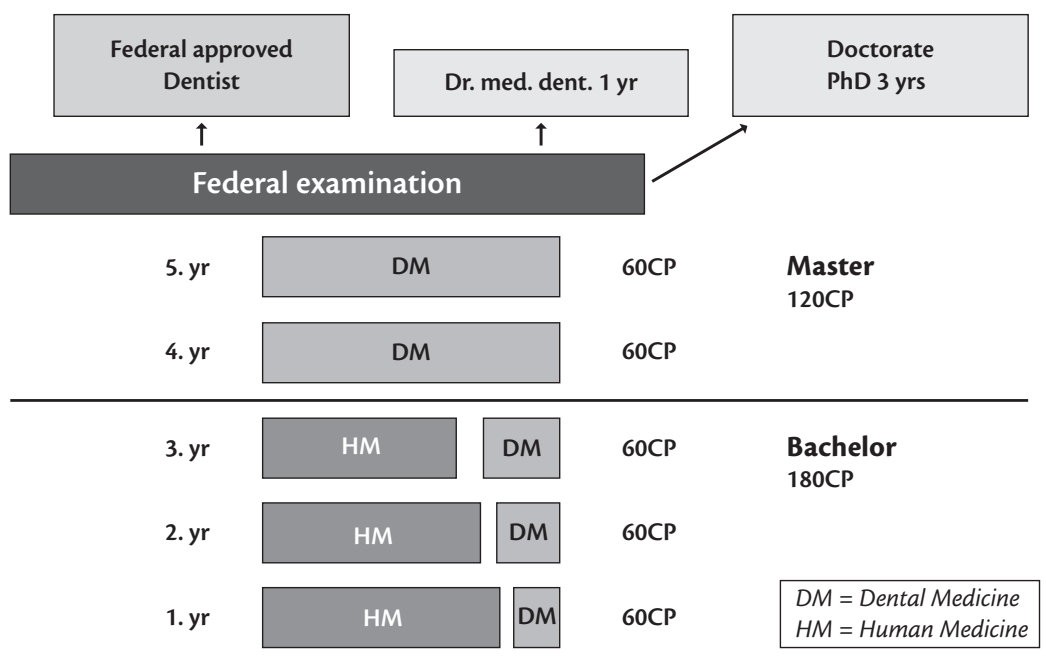

Figure 2 Bologna Model of Dental Studies

lowed by a three-year master programme ('physician track'). Clinical clerkships are part of the master programme (Figure 1). The master programme in dental medicine lasts two years (Figure 2).

The model for medical education is in line with the regulations of the Swiss University Conference and with European requirements for medical graduates. The title 'Master of Medicine' is obligatory for admission to the federal examination, which in turn is prerequisite for admission to postgraduate medical training in Switzerland. In order to obtain the title of 'Dr. med.' (Doctor of Medicine), students have to complete a year of scientific work and write a dissertation, which can be based on their master's thesis. It should be noted that the title 'Dr. med.' is not equivalent to a PhD degree. The framework for the third cycle of the Bologna process will be developed by the Conference on Academic Medicine ('Konferenz für Hochschulmedizin') in due course.

\section{Implementation of Bologna in Basle: Physician track}

In the autumn of 2006, the first cohort of students started with the bachelor programme in Basle. Behind the scenes, an organizational marathon had to be accomplished. Within the shortest possible time, the whole curriculum had to be changed from the old three-cycle system to the new two-cycle system. This necessitated major changes. The old curriculum, consisting of three two-year cycles: 1 ) the healthy body, 2) the sick body and 3) clinical rotations and synthesis, had to be redesigned to fit the two-cycle Bologna system, with three years for each cycle. Reworking the three-cycle system, in which the organ-related units were spread over four years, into the two-cycle system gave rise to the idea to present organ-related systems twice, once during the bachelor programme and once during the master programme. In this way a cyclic process of cumulative learning was created. 
Changes in the bachelor programme were based on programme outcomes defined by the curriculum committee, which were based on the notion that the bachelor programme is an integral part of the master programme. Graduates must have a sound understanding of the healthy body and the sick body. In order to acquire this understanding, they attend integrated, interdisciplinary modules, with organ systems as the organizing principle. Graduates must also possess relevant knowledge and skills in basic and social sciences in order to be able to recognize and classify clinical symptoms and clinical pictures. They must also possess practical skills and scientific competencies and be able to demonstrate adequate professional behaviour in a medical setting. The Bachelor's degree does not qualify students to practise medicine.

The outcomes required for the degree of 'Master of Medicine' are defined by the federal law for the medical professions ('Universitäre Medizinalberufe'; 'Medizinalberufegesetz') and by the SCLO, which sets the level of competence required to pass the federal examination. It does not define the level of competence for the Bachelor's degree in medicine, however, and the definition of this exam is left to the medical faculties.

The bachelor programme consists of an obligatory core curriculum and one of two optional courses (in Basle these are called 'obligations' and 'majors', respectively). The mandatory programme consists of organ-based modules and a longitudinal programme in 'basic and advanced competencies'. Additionally, students choose between the major in 'clinical medicine' and the major in 'dental medicine'. During the first two years, about five to ten percent of curricular time is dedicated to the majors. After two years, the students in the two majors follow fully separate programmes.

\section{Core curriculum: obligations}

As mentioned above, linkage between the bachelor and the master programmes is realized by means of a structure in which most of the organ-based modules from the bachelor programme are repeated in the master programme. During the first three years, the emphasis is on basic and social sciences, anatomy, biochemistry, physiology and pathology, but courses include some clinical aspects and patient problems as well. The master programme focuses on clinical subjects: signs and symptoms, clinical reasoning, diagnostics and therapeutic procedures. Principles from basic sciences, physiology and pathology are revisited in the context of clinical problems. This concept supports a learning spiral and cumulative learning (Figure 3).

Each of the key units that determine the structure of the bachelor and the master programmes focuses on one organ system. The modules of the bachelor programme are coordinated by basic science teachers, which are co-coordinators of the modules dealing with the same organ system in the master programme. With clinical teachers, the process is the same but in reverse order. In the master programme clinical teachers coordinate the modules which they co-coordinate in the bachelor programme. This structure helps to forge strong interconnections and transfer of content between the bachelor and the master programmes.

The longitudinal programme in 'basic and advanced competencies' covers clinical skills, social and communication skills, scientific competencies, humanities and ethics, and runs throughout the whole of the six-year curriculum. The programme comprises specific courses that 


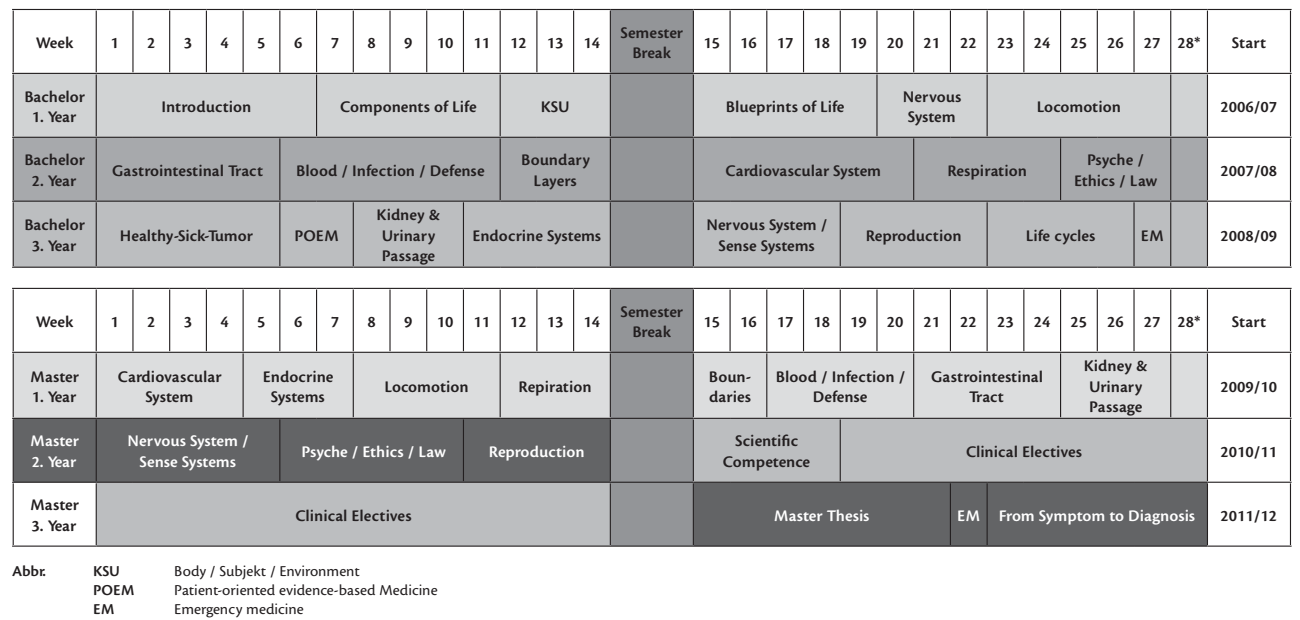

Figure 3 The Basle bachelor and master programmes

are delivered in parallel with the related organ-based modules. In order to embed the teaching of the competencies in clinical subjects, core content of the programme is also integrated in the organbased modules (Figure 4).

\section{Options: the majors in clinical and dental medicine}

Initially, the Basle faculty offered other majors besides clinical medicine and den- tal medicine, such as public health and biomedical sciences, which helped students to gain knowledge and experience in those fields. It was planned that students undertaking the additional majors would take the federal exam at the end of their studies. Of all first year students (approximately $170-180$ students, $130-140$ medical students, 40 dental students), eight percent did the 'Public Health' major and eight percent did the 'Biomed-

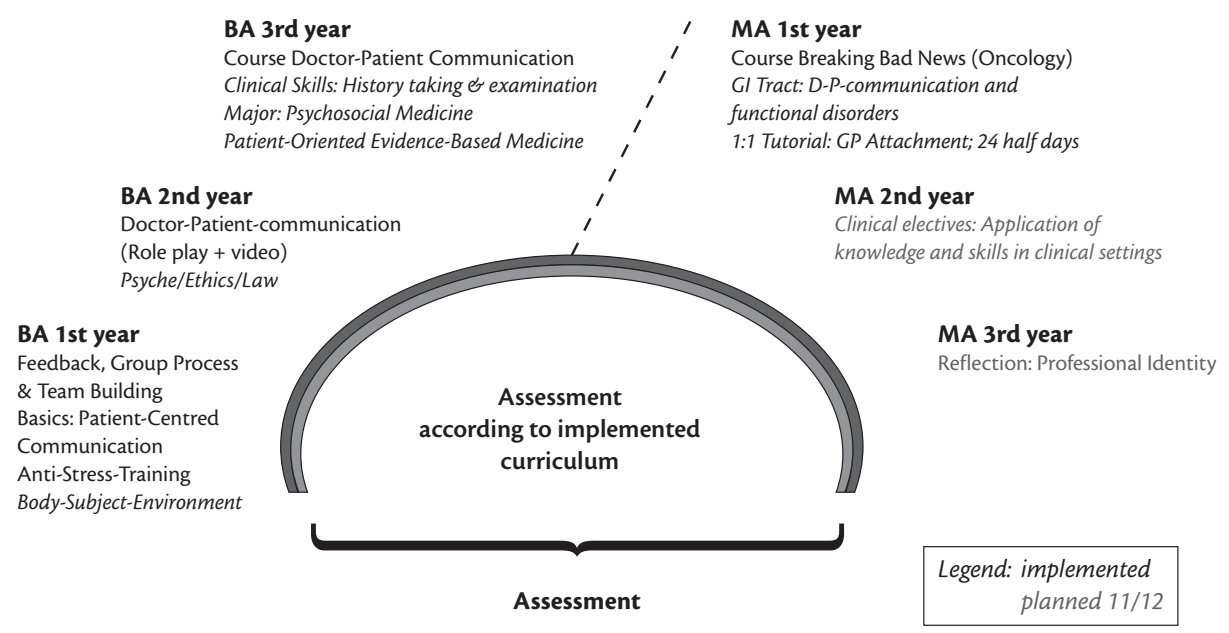

Figure 4 Longitudinal programme in communication and social competencies 
ical Sciences' major. It soon became clear, however, that the plan to provide students with knowledge in these two fields while at the same time preparing them to meet the requirements of the medical programme had been overly ambitious and after two years these two majors were abandoned. Competition with new master programmes in the basic sciences played a major role in this development as well.

As part of the clinically oriented programme, students choose, from a range of topics, one that is of special interest to them. In small groups, guided by a tutor, they study clinical topics, scientific aspects related to organ-based modules or specific topics from biomedical sciences or public health. During the second year of the programme, they spend three nights in an emergency room shadowing nurses. During the fourth year students undertake an obligatory attachment in general practice with one to one teaching.

At the medical faculty of Basle, three assessment formats are used: multiple choice questions, OSCE and portfolio. Objectives and content of the organ-based modules are mainly assessed by multiple choice tests at the end of each semester. Basic and advanced competencies are assessed annually by one or two OSCEs, and the portfolio is used to assess students' competence in relation to the majors. The Bologna model ideally requires end-ofmodule exams to which credits can be assigned, but this would involve up to eight assessments per year, which would be too much of a burden on the resources of the Basle faculty. As a result, the federal system of one assessment at the end of each semester is retained for the time being.

One-year clinical rotations in both the fifth and the sixth year are an integral part of the master programme. Students have to obtain 60 credits for each rotation. Assessment takes the form of a log- book, based on the SCLO clinical objectives. Medical doctors who are in contact with the students during the attachments in general practice, the clinical courses and ward-based clinical teaching sign the objectives in the log-book to confirm that students have met them. Students can start to collect signatures from the beginning of the master programme.

A major challenge for the whole faculty is the implementation of the Master's thesis. According to the SMIFK requirements, the Master's thesis involves a workload equivalent to at least 15 credits. The expected workload involved in supervising 130 to 140 Master's theses annually should not be underestimated and this curricular component therefore requires attention within the framework of faculty development and change management.

In the summer of 2009, the first 'Bachelor of Medicine' degrees were awarded. Nearly all of the students completing the bachelor programme proceeded with the master programme. The future will tell which new occupational fields and alternative study programmes will be open to Bachelors of Medicine. At this point in time, we could envisage master programmes in medical informatics, biomedical engineering, public health, and possibly others. The bachelor programme in medicine provides students with a sound understanding of the structure and function of the human body and with first clinical experiences and insight into clinical work. This profile might be suitable for a variety of occupational fields, such as pharmaceutics, health insurance, etc., which do not need fully trained medical doctors but welcome graduates with a good understanding of the human body.

\section{Achievement of the Bologna Goals}

With the implementation of the two-cycle system, the ECTS credit system, diploma 
supplements and coherent quality assurance in all the medical faculties, the major Bologna goals can be said to have been achieved in medical education in the whole of Switzerland. The framework for the third cycle of the Bologna requirements, the $\mathrm{PhD}$ phase, will be developed in due time.

Other Bologna goals, like more mobility for students, have not been achieved yet. The fact that medical schools design their curricula independently, both nationally and internationally, has resulted in considerable curricular variation. Currently, no national requirements for medical programmes, such as uniformity in sequencing and length of modules, have been developed in Switzerland. It is therefore difficult for students to do parts of the programme elsewhere. Another Bologna goal is to offer more flexibility to students with regard to their course of study. Unfortunately, the reduction of the lecture period to 28 weeks per year counteracts that goal. The fact that annually 60 credits have to be earned during a 28 week period means very full schedules, with very little time for additional self study.

\section{Conclusion}

In summary, the implementation of the Bologna reforms in Switzerland has been successful, especially with regard to the very tight time schedule. Ongoing evaluation will inevitably identify weaknesses requiring further improvement, which is only to be expected in such a fundamental process of change. Flexibility and willingness to listen to and learn from other faculties, teachers and students is called for if we are to maintain a successful process of ongoing improvement.

In Basle, difficulties arose partly from insufficient support for change management, and these have affected students and teachers in equal measure. Student- centred learning gives students a more active role, but not all of the students are prepared to meet that challenge. Uncertainty among students is also increased by the fact that students in the new programme are unable to benefit from the experiences of senior students, because all the seniors were trained in the 'old system'. This also holds true for teachers. Continuous efforts are required to keep convincing, motivating and supporting teachers in their endeavours to rethink medical education as well as their individual teaching methods. This has been the case during the entire period of curriculum change in Basle the last 15 years, not only during the implementation of the Bologna requirements. Change management is not an easy task and, furthermore, medical education has to compete with increasing demands from research and patient care. A major challenge for the future will be to achieve sustainable consolidation of high quality medical education and to keep emphasizing its importance within the faculty. Despite difficulties, the engagement in teaching and learning at the medical faculty of Basle has been more than remarkable during the many years of intensive reform.

\section{References}

1. Preamble to the Constitution of the World Health Organization as adopted by the International Health Conference, New York, 19-22 June, 1946; signed on 22 July 1946 by the representatives of 61 States. [Official Records of the World Health Organization, no. 2, p. 100] and entered into force on 7 April 1948.

2. World Health Organisation: Doctors for health. A WHO global strategy for changing medical education and medical practice for health for all. Geneva: World health organisation 1996. (http:// whqlibdoc.who.int/hq/1996/WHO_HRH_96.1.pdf; accessed 14.10.2009).

3. Joint Commission of the Swiss Medical Schools. Swiss Catalogue of Learning Objectives for Undergraduate Medical Training. 2nd Edition 2008 (http://sclo.smifk.ch/; accessed 14.10.2009). 
4. Medizinische Fakultät Basel (Medical Faculty of Basel). Interner Evaluationsbericht zum Studium der Humanmedizin an der Medizinischen Fakultät der Universität Basel im Rahmen der Pilotphase zur Akkreditierung der medizinischen Fakultäten der Universitäten der Schweiz. [Internal evaluation report on medical studies at the Faculty of Medicine of the University of Basel within the framework of the pilot accreditation process of the medical faculties of the Swiss universities]. Basel 2004. (http://medizin.unibas.ch/ fileadmin/MedFak/Dokumente/Lehre/Interner Evaluationsbericht.pdf; accessed 14.10.2009).

5. Accreditation of Swiss Medical Faculties Medizinische Fakultät der Universität Basel. External Evaluation Report of the International Group of Experts submitted to the Schweizerische Hochschulkonferenz; 1999. ( h t t p : / / medizin. unibas.ch) fileadmin/MedFak/Dokumente/Lehre/External_ Evaluation_Report_-_1999.pdf).

6. Rectors' Conference of the Swiss Universities. Hochschulmedizin 2008. Konzept zur Reform der medizinischen Lehre und Forschung an den Universitäten der Schweiz. [Draft proposal for the reform of medical education and research at the Universities in Switzerland]. 2004 (www.crus. ch/dms.php?id=826; accessed 14.10.2009).
The authors:

H.J. Kaiser, $M D P h D$, is professor and vice rector Teaching and Learning, University Basel, Switzerland. C. Kiessling, MDH, is dean Office for Student Affairs, Medical Faculty Basel, Switzerland.

Correspondence

Prof. dr. Hedwig J. Kaiser, Petersgraben 35, P.O. Box, 4003 Basel, Switzerland. Tel.: +41 612672736;

E-mail:vizerektorinlehre@unibas.ch

Dr. Claudia Kiessling, Medical Faculty Basel, Klingelbergstrasse 61, 4031 Basel, Switzerland. Tel.: +41 612657611; E-mail: Claudia.Kiessling@unibas.ch

No potential conflict of interest releant to this article was reported 